\title{
Alumbrando el principio de lo mejor: derecho natural, necesidad moral y justicia divina en el joven Leibniz (1663-1671)
}

\author{
MAXIMILIANO ESCOBAR VIRÉ \\ Universidad de Buenos Aires \\ Universidad Nacional de Quilmes
}

DOI: $10.36446 /$ rlf2020198

Resumen: El joven Leibniz abordó, primeramente, la cuestión de la justicia divina desde un enfoque iusnaturalista, basándose en la doctrina de los entes morales de Erhard Weigel. De tal doctrina tomó el concepto de necesidad moral, que emplea en este período (1663-1671) para definir la noción de obligación. Sin embargo, este enfoque jurisprudencial le resulta inadecuado para explicar la justicia divina, porque Leibniz entiende que Dios está exento de toda obligación jurídico-moral. Por ello, busca en la doctrina de la armonía universal una razón que pueda explicar la equidad o piedad divina. Y esta búsqueda parece conducirlo a esbozar, hacia 1671, el principio de lo mejor, como principio que rige las acciones divinas, basado en una concepción intelectualista de la libertad.

Palabras clave: principio de lo mejor, obligación, armonía universal, piedad. 


\title{
Giving Birth the Principle of the Best: Natural Law, Moral Necessity and Divine Justice in the Young Leibniz (1663-1671)
}

\begin{abstract}
The young Leibniz faced the question of divine justice, firstly, from the standpoint of a natural law theory, based on Erhard Weigel's doctrine of moral entities. Leibniz took from that doctrine the concept of moral necessity, which is used, in this period (1663-1671), to define the concept of obligation. However, this jurisprudential framework does not allow him to explain divine justice, because, for Leibniz, God is free from any moral-juridical obligation. Therefore, Leibniz seeks in the doctrine of universal harmony a reason to explain divine equity or piety. And it seems that this search takes him to introduce, by 1671, the principle of the best, as a principle that rules divine actions, based on an intellectualist conception of freedom.
\end{abstract}

Key-words: principle of the best, obligation, universal harmony, piety.

\section{Introducción}

$\mathbf{W}_{\text {hace tiempo, en una temática que bien podría formularse me- }}^{\text {is invaciones sobre Leibniz se vienen centrando, desde }}$ diante la siguiente pregunta: ¿Por qué el Dios leibniziano es justo? ¿Cuál es la razón (ontológica y/o moral) que explica el atributo de la justicia en Dios?

Leibniz ha contestado muchas veces esta pregunta. Tal vez, su versión más clara se encuentra en la Meditación sobre la noción común de justicia, de 1703 (Leibniz Mollat, 60). Esta cuestión se encuentra, a mi juicio, estrechamente ligada a un elemento vital de la filosofia leibniziana sobre el cual también he venido trabajando desde hace tiempo: el principio de lo mejor. Como todo principio, se trata de una verdad que debiera constituir el fundamento último para un cierto género o una clase de verdades (ya sea que se derive, él mismo, de otros principios más generales o no). Ahora bien, algunos de los problemas a que da lugar este principio son los de precisar i) cuál es la clase específica de verdades sobre las que rige, así como ii) cuándo aparece en la filosofia leibniziana.

Sin embargo, este principio no estuvo a la base de la primera vía que Leibniz adoptó para explicar la justicia divina. Este trabajo intenta elucidar si, acaso, los problemas suscitados por los primeros intentos leibnizianos de fundamentar la justicia divina constituyeron una de las primeras motivaciones que impulsaron a Leibniz a invocar, en su filosofia, el principio de lo mejor. 


\section{Un Dios legibus solutus}

$\mathrm{C}^{1}$ punto de partida de la reflexión leibniziana sobre la justicia de

CDios se encuentra, a mi juicio, en la conocida anotación de 16631664 al Compendium metaphysicae de Daniel Stahl, en la cual Leibniz afirmaba que "Dios no es causa moral del pecado", dado que

[...] 1. causa moral es solo en actos morales, es decir, en orden a la ley; 2. es causa moral solamente aquella a la cual la ley le es dada. De esto se sigue que Dios no puede ser causa moral, porque la ley no es dada para Dios. (Leibniz $A$ VI 1,27)

El primer esbozo de una justificación divina, imaginado por un Leibniz de 17 años, se resume en esto: Dios no es moralmente responsable por la existencia del pecado, pero no porque su acción sea justa, sino porque Dios está fuera de la jurisdicción de toda ley moral. Es decir, a Dios no se le puede imputar la justicia o injusticia de sus acciones. Es inimputable en términos morales, o también, como dirá Leibniz más tarde, "anupeúthunos" (no responsable por sus acciones, no sometido a la obligación de dar cuentas por sus actos).

Tanto por la terminología empleada en este pasaje, como por la orientación y los intereses del pensamiento del Leibniz recién graduado en Leipzig, resulta claro que el contexto teórico de este breve argumento remite al ámbito de la jurisprudencia, y en especial, a la reflexión tardo-escolástica y moderna sobre el derecho natural. En efecto, el concepto de causa moral era propio del discurso jurídico. Pufendorf, por ejemplo, en su obra Elementorum jurisprudetiae universalis libri II (EJU) (que Leibniz ciertamente había leído ya hacia 1663), define la acción moral como la acción voluntaria del hombre en la vida social, considerada bajo la imputación de sus efectos. Este elemento formal, la imputabilidad, dice Pufendorf, confiere al agente el rango de causa moral (Pufendorf EJU, I, I, 4). Asimismo, la afirmación según la cual solo se es causa moral (o agente moral) en aquellos actos que son en orden a una ley dada, remite a una concepción de la moralidad centrada en la existencia de una ley natural, la cual establecería los preceptos morales fundamentales (constituyendo, pues, una ley moral). Tal concepción tuvo en Tomás de Aquino a su primer gran exponente (Tomás de Aquino Summa Theologiae, I-II, \$S 90-97, en especial 94), pero en los siglos XVI y XVII gozó de un renovado interés por parte de pensadores escolásticos tanto como de los

\footnotetext{
${ }^{1}$ Véanse Salas: 174, Dutens: IV, 3, 280; también Grua: 474, 431, 452.
} 
iusnaturalistas modernos, a raíz de los procesos históricos que impulsaron la búsqueda de un derecho internacional o una jurisprudencia universal (inspirado en el antiguo jus gentium). Por último, cabe notar que el interés de Leibniz entre 1663 y 1668 parece estar principalmente orientado hacia el campo disciplinar del derecho, en el que habría de desarrollar su profesión. Así lo prueban sus escritos del período, con la notable excepción de la Dissertatio de arte combinatoria (1666) y de algunas notas filosóficas. Es comprensible que así fuera, dado que Leibniz esperaba graduarse como Doctor en Leyes. Sin embargo, su interés por la jurisprudencia habría de prolongarse por el resto de su vida, no solo en razón de su profesión, sino también por su conexión con la problemática filosófica de la propia Teodicea.

He aquí, entonces, el problema que subyace a las primeras reflexiones en torno a la justicia divina: el Dios leibniziano, ¿está fuera de la jurisdicción de la ley moral, o está dentro de su jurisdicción y sometido a ella? En otras palabras, ¿está también sujeto a la obligación que impone dicha ley, o él no puede ser juzgado por dicha ley? Si Dios no estuviera sujeto a ley moral alguna, entonces, ciertamente, no se le podría atribuir responsabilidad moral alguna por la existencia del pecado. No sería necesario defender su causa. Pero tampoco podríamos tener certeza alguna de que tal Dios actúa con justicia, ya que, en definitiva, no tendría por qué hacerlo. No estaría obligado a hacerlo. ¿Qué razón tendría, entonces, Dios, para obrar con justicia?

El problema reside, entonces, en esclarecer cuál es la relación específica que mantiene el Dios leibniziano con la ley moral, o con los preceptos que establecen qué es lo justo y lo injusto. Esos preceptos son, para el joven Leibniz, el corazón de la doctrina del derecho natural. Por ello, gran parte de este problema depende de la concepción leibniziana del derecho natural y de la noción de obligación que atribuía a tal derecho.

\section{Voluntarismo vs. intelectualismo}

Como señalan Haakonssen y Schneewind, en la escolástica previa teorías del derecho natural: una vertiente nominalista-voluntarista (inspirada en autores como Duns Escoto y Guillermo de Ockham) y otra realista-intelectualista. ${ }^{2}$ Para la concepción voluntarista, Dios no está sometido a la ley natural. Ello se debe a que toda ley, en cuanto tal, requiere de un acto de

${ }^{2}$ Véanse Haakonssen 1998: 1318 y Schneewind 2010: 68. 
voluntad legislativa para ser establecida.Y como toda ley impone una obligación, solo puede provenir de un superior, alguien que detenta el poder para hacerla cumplir. Así, no habría ley moral alguna si no mediara un acto de la voluntad de Dios estableciendo la ley natural. Ahora bien, Dios no puede estar sometido a la obligación de acatar esa ley, ni ninguna otra, dado que no hay ningún superior que pudiera imponer una obligación a Dios. Toda obligación requiere, como condición necesaria y fundamental, ser emanada de un superior. El punto débil de esta posición reside en que, eventualmente, la superioridad del legislador le permitiría establecer cualquier precepto como ley, por lo que Dios podría haber decretado incluso preceptos contrarios a los que decretó. Suárez, en su Tractatus de legibus ac Deo legislatore (1612), intentaba escapar a este voluntarismo extremo, planteando que si bien Dios no está sometido a la ley eterna (cuya participación en la criatura racional es la ley natural), su voluntad es recta per se (al igual que su entendimiento), por lo cual Dios hace lo que dice la ley sin estar sometido a ella (Dios "es ley para sí mismo") (Suárez DL, II, II, 6). Por ello, no es su voluntad la que hace buenas o malas a las acciones, sino que son las esencias de las cosas las que así lo determinan, y él "prohíbe lo que es malo porque es malo" (Suárez DL, II,VI, 7).

Una concepción voluntarista era también defendida por Pufendorf, autor que habría de influir fuertemente en el joven Leibniz. La ley natural depende de la libre voluntad de Dios, quien la ha establecido por su conformidad con la naturaleza racional y social del ser humano. Ahora bien, Dios podría cambiar esa ley, ya que nada le impediría modificar la naturaleza de la criatura racional. No parece haber ninguna necesidad que haya compelido a Dios a crear al ser humano, ni a crearlo del modo en que lo creó (Pufendorf EJU, I, XII, 14). En tal sentido, Pufendorf deja en claro que la ley natural es natural, justamente, porque es adecuada a la naturaleza humana, y no impone ninguna necesidad sobre la voluntad del creador (cosa que difícilmente podría ocurrir, siendo que Dios carece de un superior que pudiera obligarlo). El problema de la arbitrariedad de la ley se planteará también para Pufendorf, quien (en su obra posterior, De jure naturae et gentium) habría de recurrir a la teología natural, sosteniendo que Dios ha elegido la naturaleza humana y la ley natural para beneficio del propio ser humano (Pufendorf DJN, II, 3, 4-5).

Sin embargo, antes que Pufendorf, Hugo Grocio, reivindicado por muchos como el fundador del iusnaturalismo moderno o secular (Schneewind 2010: 74-75), había enarbolado otra respuesta posible al problema aquí planteado. En su obra de 1645, De jure belli ac pacis, Grocio defendía una concepción claramente intelectualista, al afirmar que

El derecho natural es un dictado de la recta razón, que indica que alguna acción por su conformidad o disconformidad con la misma naturaleza ra- 
cional, tiene fealdad o necesidad moral, y de consiguiente está prohibida o mandada por Dios, autor de la naturaleza. (Grocio DJBP, I, X, 1)

Los actos sobre los que recae esta norma "son lícitos o ilícitos de suyo" (Grocio DJBP, I, X, 2) por sí mismos, con lo cual puede verse que su obligatoriedad no surge del mandato de un superior. Más aun, este derecho es inmutable, ni siquiera el propio Dios lo puede cambiar (como no puede hacer que dos más dos no sea cuatro), sino que él mismo es juzgado por dicha norma (Grocio DJBP, I, X, 5). De allí el famoso "etiamsi daremus" grociano, según el cual el derecho natural mantendría su obligatoriedad aun suponiendo que Dios no existiera o no se preocupara por los asuntos humanos (Grocio DJBP, Prolegomena, 11).

Así, en la concepción intelectualista de Grocio, las leyes naturales imponen obligación por sí mismas, con total independencia de que exista un superior o una autoridad que encarne el poder coercitivo de hacerlas cumplir. La obligación moral nace de la sola ley o de la recta razón. Más aún, Dios mismo está alcanzado por la obligatio que imponen las leyes morales. Esta posición resultaba ciertamente problemática, ya que a los restantes teóricos del derecho natural les resultaba incomprensible la existencia de una obligación cuya fuerza vinculante no emanara de un poder superior.

El problema, entonces, puede formularse también del siguiente modo: las leyes morales, para el joven Leibniz, ¿imponen obligación por sí mismas, o su obligatoriedad nace de la voluntad divina en tanto mandato de un superior? Y si valen por sí mismas, ¿son inmutables y/u obligatorias para el mismo Dios?

\section{Los entes morales}

Z1 escrito jurídico más importante de Leibniz, antes de sus Ele- $m e n t a$ juris naturalis, es el Nova methodus discendae docendaeque jurisprudentiae, de 1667. En dicha obra puede verse que la reflexión filosófico-jurídica del joven Leibniz se construye tomando, como uno de sus fundamentos, la doctrina de los entes morales de Erhard Weigel.Ya en su Specimen quaestionum philosophicarum ex jure collectarum, de 1664, Leibniz escribía:

Y el ilustre Weigel, profesor de matemática en Jena, mi preceptor y respetado protector, estableció tres máximos géneros de entidades: natural, moral y nocional, y en cada uno de ellos busca la cantidad o estimación, la cualidad y la acción. Reduce, por ende, los derechos a cualidades morales, y así como el espacio es el sustrato de la acción natural o movimiento, del mismo modo el 
Estado es como un espacio moral, en el cual el cuasi-movimiento moral es ejercido. (Leibniz $A$ VI 1,94)

Leibniz no deja de recordar que Pufendorf, en su obra EJU, también tomó estas ideas de Weigel. Esta misma filiación intelectual es uno de los elementos que conecta y emparenta la reflexión jurídica leibniziana con la de Pufendorf. Así, en el Nova methodus, Leibniz afirma:

Ahora bien, la moralidad, es decir, la justicia o injusticia de las acciones, se origina a partir de la cualidad de la persona que actúa en orden a la acción, surgida a partir de acciones precedentes, la cual es llamada cualidad moral. Sin embargo, como la cualidad real en orden a actuar es doble, potencia de actuar y necesidad de actuar, así también la potencia moral es llamada derecho, la necesidad moral es llamada obligación. (Leibniz $A$ VI 1,301)

Aquí aparece el concepto de necesidad moral, como definiens de la noción de obligatio, en el contexto de una analogía (de inspiración metafísica, cabe notarlo) entre los entes naturales y las relaciones o los conceptos morales y jurídicos (los entes morales de Weigel). Esta analogía es el primer elemento de juicio con que contamos para entender el significado de esta noción de necesidad moral, que Leibniz empleará en su discurso jurídico de sus años de juventud, y que reaparecerá en sus años maduros ya en el contexto de la Teodicea. Aquí, la necesidad moral es el análogo jurídico de la necesidad real que pesa sobre los entes reales. Se trata de una necesidad, cabe inferir, puesto que entraña un impedimento o una imposibilidad de obrar del modo contrario, pero esta imposibilidad no es natural o física, no es fáctica, sino moral. En otras palabras, sería una necesidad que no se impone sobre los cuerpos (cual ley natural), sino más bien sobre las almas, sobre la libertad de acción del agente moral.

Esto no nos dice mucho, aún, sobre el significado de esta noción de necesidad moral. A continuación, sin embargo, Leibniz comienza a despejar algunas dudas sobre la cuestión principal aquí abordada, al afirmar que "Dios es sujeto de derecho pleno hacia todas las cosas, pero de ninguna obligación" (Leibniz $A$ VI 1, 301).Y Leibniz aclara que habla

[de] la obligación estrictamente dicha, la cual desciende del mero derecho, porque todas las cosas que están en su posesión y potestad perpetua no pueden ser adquiridas o abandonadas según el mismo [derecho]. (Leibniz $A$ VI 1, 301, n.)

Hasta aquí, Leibniz parece ratificar, al menos en parte, su posición del 
argumento de 1663-1664: Dios no es sujeto de obligación alguna. Mas, cabe preguntar, ¿cómo entiende Leibniz la “obligación estrictamente dicha”? Aquí hay una pista para elucidarlo: tal obligación "desciende del mero derecho", esto es, nace de una cierta ley. De allí la importancia de clarificar la noción de necesidad moral. Por lo demás, cabe notar que la aclaración leibniziana sugiere que hay un vínculo de posesión no jurídico entre Dios y la creación, un vínculo más bien metafísico, que funda una potestad o autoridad perpetua, y que por tanto va más allá de una relación de propiedad concebida en los términos del derecho romano. Pero Leibniz no aclara mucho más.

\section{La necesidad moral como "brida moral" en Pufendorf}

Tna vía que puede acercarnos a la comprensión leibniziana de la necesidad moral, en este período, es atender a cómo concebía Pufendorf esta noción. Ya en su carta a Thomasius de setiembre de 1663, Leibniz critica duramente a Maquiavelo y a Hobbes, cuestionando al primero por reducir el derecho natural a un mero acuerdo entre personas privadas y al segundo por reducir la justicia a la utilidad del soberano. Allí se pregunta si no habrá un "antagonista" capaz de igualar la sutileza de Hobbes en el campo del derecho natural.Y contesta que él solo conoce a uno capaz de ello: Pufendorf (de quien, comenta, se dice que basó su obra EJU en una Ethica Euclidea manuscrita de Weigel) (Leibniz A II 1,3). Esto muestra, por un lado, que el Leibniz recién egresado de Leipzig tenía una cierta valoración positiva por la figura de Pufendorf (valoración que luego habría de cambiar); por otro lado, revela que Leibniz era favorable a una concepción más bien realista y no voluntarista de la noción de justicia, como ha sostenido Rateau (Rateau 2008: 66). Habría, pues, un criterio de justicia independiente de la voluntad del soberano o de los acuerdos entre individuos.

La doctrina de Pufendorf sobre los entes morales no aparece desarrollada ni expuesta en EJU (la obra que Leibniz leyó en estos años) con el detalle que alcanzará en su obra posterior, de 1672, De jure naturae et gentium $(D J N)$. Sin embargo, el esbozo de tal doctrina en EJU es coherente y compatible con su versión posterior. Pufendorf afirma ya que a la acción voluntaria se atribuyen ciertas afecciones, entes morales que constituyen modos (en el sentido metafísico de su dependencia respecto de entidades subsistentes per se) por los cuales la acción es denominada y definida de una cierta manera (Pufendorf EJU, I, XV). Esto anticipa su posterior definición de los entes morales como modos creados por los seres reflexivos y añadidos a las entidades físicas con el fin de dirigir o moderar los actos de la voluntad (Pufendorf DJN, I, I, 2-3). Estas afecciones son de dos clases: las estimativas, que refieren 
a las cantidades o estimaciones de los actos, y las denominativas o determinativas, que son las cualidades "por las cuales las acciones son llamadas necesarias o innecesarias, lícitas o ilícitas, buenas o malas, justas o injustas" (Pufendorf EJU, I, $\mathrm{XV}, 1)$. Ahora bien, Pufendorf aclara que una acción es necesaria para alguien cuando esa persona ha recibido la ley o la orden de un superior, por lo cual la persona es compelida a hacer lo que dice la ley (Pufendorf EJU, I, XVI, 2). Aquí parece encontrarse el significado de la necesidad a la que Pufendorf califica como moral.

En la Definición XII, Pufendorf define la obligación como "la cualidad moral operativa por la cual alguien está atado (tenetur) a realizar (praestare), admitir o padecer algo". Resuena aquí la terminología empleada por el propio Leibniz.Y luego aclara que

Concuerda con esta definición aquella común de los jurisconsultos, por la cual definen la obligación como un vínculo jurídico (vinculum juris), por el cual somos compelidos a realizar (praestare) alguna cosa. Pues por ella es introducida una especie de brida (fraenum) moral sobre nuestra libertad de actuar, por la cual no podemos rectamente (recte) tender hacia algo diverso a la parte a la que ella conduce; aun cuando ninguna obligación tiene tal eficacia natural como para sujetar la libertad natural de nuestra voluntad de tal modo que [esta] no pueda, al menos de hecho, dirigirse hacia otras cosas. (Pufendorf EJU, I, def. XII, 1)

Dos elementos son interesantes en este pasaje. En primer lugar, la metáfora de la "brida moral", que parece revelar el sentido de la necesidad moral, entendida como una suerte de freno interior impuesto sobre nuestra libertad de actuar. En segundo lugar, la aclaración de que subsiste, en el agente, la posibilidad física o "de hecho" de no acatar la obligación, lo cual marca la diferencia entre la modalidad jurídica aquí introducida respecto de las modalidades físicas. ${ }^{3}$

Ahora bien, como se vio, la necesidad moral, como cualidad determinativa de nuestras acciones, tiene su fuente en una ley. Pufendorf define la ley, en la Definición XIII, como el decreto por el cual un superior compele a un súbdito a dirigir sus actos de acuerdo a tal decreto. Allí afirma que

[...] aun cuando la ley no deba carecer de sus razones, estas, con todo, no son propiamente las causas por las cuales esta misma ley es provista de obligación,

\footnotetext{
${ }^{3}$ Véase también EJU, Obs. II, 9.
} 
sino la potestad de quien la prescribe, quien, una vez que hubo significado su voluntad, impone (adsert) al súbdito la obligación de actuar en todo de acuerdo con su prescripción, aunque quizás las razones por las que la misma ha sido prescripta de tal modo no sean tan claras para este. (Pufendorf EJU, I, def. XIII, 1)

Pues es vano mandar (praecipere) sobre alguien aquello que puede ser impunemente ignorado. De ahí que nadie esté obligado por las leyes de una persona o grupo que no posea potestad alguna sobre aquel.Y la facultad de imponer algo por medio de ley o de prescripción implica superioridad [...] (Pufendorf EJU, I, def. XIII, 4)

Aquí se hace evidente el voluntarismo de Pufendorf. La necesidad moral sería, para este autor, el constreñimiento interior de la propia voluntad del agente (la "brida moral"), motivado o causado por la coerción exterior del poder del superior que prescribe la ley. No es, como en Grocio, una necesidad emanada de la sola razón (desprovista de toda coerción). Aquí, el intelecto del agente ciertamente juega un rol: comprende y asume la necesidad de acatar la norma porque la autoridad que la prescribe tiene el poder de forzar al individuo a cumplirla. Pufendorf también sostiene que una autoridad es legítima solo cuando ha surgido por el consentimiento de aquellos sobre quienes ha de mandar, a través de un pacto, lo cual es consecuencia de la igualdad natural de todos los seres humanos. Pero también señala que, una vez establecida la autoridad, la misma no puede ser desobedecida, aun si nos desagrada, ya que la propia ley natural obliga a cumplir los pactos (Pufendorf EJU, II, II, 3). En tal sentido, Pufendorf deja en claro que las razones de la ley pueden no ser claras, pero que eso no suprime su obligatoriedad, ya que, al menos en EJU, las razones no generan la obligatoriedad de la ley.

Desde esta perspectiva, resulta claro que en Dios no puede haber obligación alguna, ya que no hay nadie superior a este. Y la necesidad moral tiene su fundamento en el mandato y la autoridad de un superior. ¿Es esta también la concepción de Leibniz? Su tesis del Nova methodus, según la cual Dios no es sujeto de obligación alguna, no deja de ser compatible con una concepción voluntarista de la obligación, como la expresada por Pufendorf. El desafio que se plantea para Leibniz es cómo justificar esta tesis sin caer en una concepción voluntarista, ni tampoco en su propia postura de 16631664, según la cual Dios no es causa moral. 


\section{La piedad y el doble fundamento del derecho natural}

Etre los parágrafos 71 y 75 del Nova methodus, Leibniz aborda el más bien los principios” (Leibniz $A$ VI 1, 342). Enuncia primero cuál fue el fundamento propuesto para tal derecho por ilustres pensadores antiguos y "recientes" (Platón, Aristóteles, los estoicos, Grocio, Hobbes y otros). Leibniz se propone conciliar "fácilmente" las diversas opiniones de estos autores, y sostiene que hay tres grados del derecho natural: derecho estricto, equidad y piedad. De estos grados, dice, el que sigue es más perfecto al que antecede, y lo deroga en caso de conflicto (Leibniz $A$ VI 1, 343).

El derecho estricto o mero derecho, dice Leibniz, desciende de la definición de los términos, y en él se basa el derecho de la guerra y de la paz. Su precepto es "no hacer daño a nadie, ni darle derecho a la guerra". En él se basa la justicia conmutativa (Leibniz $A$ VI 1,343). El segundo grado del derecho natural, la equidad o igualdad, es la razón o proporción entre dos o muchos, y consiste, dice Leibniz, en armonía o congruencia. Esto sugiere que también este grado se basa en la definición de los términos (aunque Leibniz no lo afirma expresamente) (Leibniz $A$ VI 1, 343-344). El tercer "principio" del derecho natural, dice ahora Leibniz, es la voluntad del superior. Ahora bien, el superior puede ser por naturaleza o por pacto. Por naturaleza es Dios. Su voluntad es o bien natural, de allí la piedad, o bien la ley, de allí el derecho divino positivo. La piedad, por tanto, es el tercer grado del derecho natural, y le confiere a los restantes perfección y efecto.Y Leibniz afirma:

Puesto que Dios, porque es omnisciente y sabio, confirma el mero derecho y la equidad; porque es omnipotente, lo hace cumplir (exequitur). De aquí que coincida la utilidad del género humano, y por cierto la belleza y armonía del mundo, con la voluntad divina. [...] Por este fundamento, no está permitido abusar ni siquiera de uno mismo, porque nosotros mismos pertenecemos a Dios (nos ipsimet sumus Dei), a quien la omnipotencia le confiere derecho sobre todas las cosas. De aquí el precepto de aquel: vivir honestamente. Siempre que el derecho estricto y la equidad carezcan de vínculo físico, Dios les añade la ejecución, para que aquello que es útil públicamente, esto es, al género humano y al mundo, eso mismo sea también útil al individuo; y así, por ende, para que todo lo honesto sea útil, y todo lo feo, perjudicial. Porque consta, en base a su sabiduría, que Dios ha destinado premios a los justos y penas a los injustos [...] (Leibniz $A$ VI 1,344)

En esta exposición, resulta claro que los primeros dos grados del derecho natural (derecho estricto y equidad) derivan, para Leibniz, de la definición 
de los términos o las nociones jurídicas. Hay, pues, una concepción intelectualista del contenido del derecho natural y sus preceptos: lo justo es justo per $s e$, en virtud de las solas nociones (derecho, justo), y no requiere de la voluntad de un superior para ser establecido como justo o equitativo.

Sin embargo, Leibniz también eleva la voluntad del superior al rango de principio del derecho natural, del cual se sigue su tercer grado. Este "principio" aporta, ante todo, la ejecución o el cumplimiento, a través del elemento coercitivo (la pena), sin el cual los dos primeros grados podrían carecer de un "vínculo físico" con el mundo. Por eso Leibniz afirma, a continuación del pasaje citado, que la existencia de Dios es "el fundamento último del derecho natural" (Leibniz $A$ VI 1, 344-345). Este principio es el que confiere perfección y efecto a los restantes. Hay, entonces, dos niveles de fundamentación del derecho natural y de la moralidad para el joven Leibniz, ambos necesarios: el de las nociones de lo justo y lo injusto, que funda el contenido del derecho (aportando sus razones), y el de la voluntad del superior, que funda la vigencia efectiva del derecho (aportando la ejecución o garantía de cumplimiento por medio de la coerción). La obligatoriedad de la ley moral tiene un doble fundamento de razón y coerción, una base intelectualista y otra más bien voluntarista.

En tercer lugar, al hacer coincidir los tres grados del derecho natural con los tres preceptos del derecho de Ulpiano, Leibniz plasma ya lo que habría de ser su posición constante en el campo de la jurisprudencia: la coincidencia fundamental entre el derecho romano y el derecho natural (Leibniz $A$ II 1, 56). Este último es concebido, en el Nova methodus, como un derecho instaurado (o más bien confirmado) por Dios para la criatura racional. No está presente aún la tesis leibniziana posterior de la univocidad de la noción de justicia.

Por último, lo más importante: Leibniz ya afirma aquí la coincidencia entre la utilidad del género humano, la armonía del mundo y la voluntad divina. Leibniz define en este texto la justicia como "lo útil públicamente", distinguiendo tres niveles de lo público: el mundo y su gobernador (de allí la jurisprudencia divina), el género humano (jurisprudencia humana) y la república (jurisprudencia civil) ( $A$ VI 1, 300-301). Por ende, Leibniz afirma que la voluntad de Dios coincide con la justicia para el mundo y el género humano. Dios quiere lo que es justo para la criatura humana. A esta voluntad divina de lo útil para el ser humano Leibniz la denomina aquí piedad. El concepto latino de pietas abarca un campo semántico variado, haciendo referencia a un sentimiento de amor que lleva a la aceptación y el cumplimiento de todos los deberes para con los dioses, la familia, la patria, los amigos y todo ser humano. Incluye, también, el significado de la equidad o la justicia divina. Este concepto se transformará en la noción clave de la ética leibniziana posterior, y ya aquí aparece en una doble significación: por un lado, aludiendo 
al sentimiento que lleva a los seres humanos a vivir honestamente (por estar sometidos al poder de un superior que confirma la justicia pero también la hace cumplir); por otro lado, refiriendo a la voluntad natural de Dios, su deseo de ser justo o equitativo con el mundo y el género humano.

Esta piedad divina, esta voluntad de Dios de actuar con justicia hacia el género humano, comienza a responder nuestro problema planteado aquí. Dios no está obligado a ser justo, pero lo quiere. Falta explorar las razones que Leibniz puede dar para justificar este deseo de Dios.

\section{La harmonia rerum}

T a justificación leibniziana de la piedad divina hacia las criaturas

Lracionales, entre 1666 y 1671, se apoya sobre dos pilares: una reflexión ético-jurídica y un fundamento metafísico. El pilar metafísico no es otro que la teoría de la harmonia rerum, que Leibniz toma de sus lecturas de la obra de Bisterfeld, Philosophiae primae seminarium, entre 1663 y 1666.

Como puede reconstruirse a partir de sus notas sobre dicha obra, Leibniz asume que ningún ente (salvo el Ente primero) es absoluto ni puede existir aislado, por lo cual, en definitiva, todo ente creado es "Dios con otra cosa". Por ende, los entes creados no son solitarios por naturaleza, sino que todo ente es simbiótico o pertenece a una sociedad. Así pues, el nexo de la naturaleza del universo confirma el orden y la panarmonía, la unión y comunión entre todas las cosas (Leibniz AVI 1,153). Esta panarmonía está fundada sobre la sacrosanta trinidad, y esta es fuente, norma y fin de todo orden (Leibniz $A$ VI 1, 158). Hay aquí una analogía entre la trinidad cristiana y el orden del universo, orden que implica tres términos: un término primero o a quo (la fuente), un término segundo o per quem (la norma), y un término tercero o ad quem (el fin) (Antognazza 1999: 46-47). Esta estructura se replica en la naturaleza de todo ente, al cual competen el poder, la sabiduría y el amor (elementos que Leibniz asocia con las tres personas de la trinidad) (Leibniz $A$ VI 1, 156).

Leibniz no aclara, en estas notas, el vínculo entre Dios y las criaturas. Queda claro, sin embargo, que al ente primero es a quien competen máximamente el poder, la sabiduría y el amor. Leibniz señala que el afecto es amor o deseo de unión en relación al terminus ad quem, y es amor de benevolencia o de beneficencia en relación al terminus a quo ( $A$ VI 1,156-157). Esto sugiere que Dios, por su propia naturaleza (en tanto ente), posee, prima facie, un amor de benevolencia y de beneficencia hacia las criaturas.

Como puede verse en los pasajes analizados del Nova methodus, la harmonia rerum va a adquirir un lugar central en la filosofia del joven Leibniz, convirtiéndose en fundamento i) de las nociones mismas (como en el caso 
de la equidad, que es armonía o congruencia), ii) del orden de las cosas (la "armonía del mundo"), y iii) de la propia acción divina, porque la voluntad de Dios coincide con la utilidad del género humano (y con la belleza o armonía del mundo). En esta época comienza a erigirse lo que Leibniz denominará, más tarde, el principio de la armonía de las cosas (Leibniz A VI 3, 472). La voluntad de Dios tiende al orden, quiere la armonía, porque de algún modo quiere a las criaturas, y estas no pueden existir si no es en sociedad, en una república universal (Leibniz $A$ VI 1,156). Así, en la Confessio naturae contra atheistas de 1668, Leibniz dirá que Dios, en tanto es inteligente o sabio, elige crear las cosas naturales del modo en que las crea "en razón de la belleza de las cosas" (Leibniz $A$ VI 2, 492). Más aun, la armonía en tanto orden universal ideal, parece confundirse con el mismo Dios, ya que la intuición "cara a cara" de Dios es la contemplación de "la armonía universal de las cosas", "porque Dios no es nada distinto a la armonía de las cosas o al principio de la belleza en ellas mismas" (Leibniz AVI 1, 499).Y en la carta a Arnauld de 1671, Leibniz dirá que Dios es "la sede de la armonía universal" (Leibniz $A$ II 1, 174).

\section{La alabanza como multiplicación de la armonía}

Yentonces... ¿cuál es la razón por la cual Dios es justo o actúa
con justicia?

En uno de los primeros manuscritos de los Elementa juris naturae, de 1669-1670, Leibniz comienza su intento de fundamentar el derecho natural tratando de responder al dilema de Carnéades, que también había abordado Grocio: la justicia, o bien no es nada, o bien es una estupidez suprema, porque prescribe el daño de uno mismo y el beneficio de los otros (Leibniz $A$ VI 1, 431). Para fundamentar el derecho natural, lo primero que debe demostrarse, según Leibniz, es que la búsqueda del bien propio o del placer (verdadero motor de toda acción voluntaria) (Leibniz $A$ IV 1,34-35) es compatible, en cierta medida, con la búsqueda del bien ajeno; es decir, que la prudencia es compatible o puede conciliarse con la justicia. La prudencia, decía Leibniz en 1663-1664, es "el hábito de ver qué es lo útil en todas partes", o "la ciencia de lo útil en todas las cosas" (Leibniz $A$ VI 1, 60). Por ello, si no existiera Dios alguno (como propone pensar Grocio) y el alma no fuese inmortal, la justicia sería una estupidez (una negligencia hacia la propia utilidad) (Leibniz $A$ VI 1, 431).

La justicia, propone Leibniz como primera definición, consiste en "la prudencia en el asistir o en el dañar a otros" (Leibniz $A$ VI 1, 434), es decir, la búsqueda de una adecuada proporción entre la utilidad privada y la utilidad 
pública. Esto lo lleva a pensar en diversas situaciones posibles, en las que debe esclarecerse cuál utilidad es la que prima sobre la otra. Allí sostiene que "Dios es justo aunque no siga ninguna de estas reglas, porque no obstante es prudente". Esto significa que Dios es justo, ante todo, porque quiere aquello que es bueno para sí mismo, pero ello de algún modo conlleva el bien para las criaturas, "a no ser que sea por casualidad que a él le plazca que los hombres se amen" (Leibniz $A$ VI 1, 434).Y Leibniz escribe:

Con todo, esto en cierto modo le place y en cierto modo no, porque tiene otro principio, la armonía universal. (Leibniz $A$ VI 1,434)

A continuación, plantea el problema fundamental: si hubiese alguien tan poderoso que no tuviera por qué temer la ira de los otros, ese alguien no tendrá, basándose en la prudencia, motivo alguno para ser justo, si acaso no lo deleita la alabanza o la buena opinión de los otros sobre él (Leibniz $A$ VI 1,434).A ello responde que cualquier ser de esta índole será deleitado por esta alabanza o buena opinión, "porque todo sabio es deleitado por la belleza o armonía" (Leibniz $A$ VI 1,434-435). Como la justicia es una forma de prudencia, no hay otra razón para ella que el premio o el castigo, es decir, aquello que redunda en el propio beneficio o perjuicio. Y Dios mismo no escapa a esta regla: Dios, dice Leibniz, "es su propio premio" (Leibniz $A$ VI 1, 435).

Como sostiene Francesco Piro, la estrategia de Leibniz en este escrito consiste en hacer del concepto de alabanza (laus) un medio para multiplicar la armonía (Piro 1999: 161-163). ${ }^{4}$ Leibniz escribe:

Y no hay sabio que no busque eso [la alabanza], puesto que busca la armonía. La alabanza es, pues, como un eco de la armonía, y un reflejo tanto como una duplicación. Si Dios no tuviera criaturas racionales en el mundo, tendría la misma armonía, pero desprovista de eco, la misma belleza desprovista de reflexión y de refracción o de multiplicación. Por lo cual la sabiduría de Dios exigía criaturas racionales, en las cuales las cosas se multiplicaran. Una mente es, pues, algo así como un mundo en un espejo [...] Por tanto, se sigue que habremos de satisfacer a aquellos que pueden estimarnos bien o mal, si somos prudentes. (Leibniz $A$ VI 1,438)

\footnotetext{
${ }^{4}$ Piro considera que Leibniz probablemente tomó esta noción del deseo de alabanza de Sforza Palavicino, para quien tal deseo constituía un instrumento de Dios para volver a los hombres virtuosos (Piro 1999: 162).
} 
Leibniz definirá la noción de armonía, hacia 1671, como la "diversidad compensada por la identidad" (Leibniz $A$ VI 1, 484), la "similitud en las cosas disímiles" (Leibniz $A$ II 1,98). También definirá al placer o deleite como "la percepción de la armonía", y a lo bello como aquello "cuya armonía es comprendida clara y distintamente" (Leibniz $A$ VI 1, 484), definición que remite a la función del entendimiento. Ello le permitirá dar un fundamento demostrativo a la tesis según la cual "todo sabio es deleitado por la belleza o armonía". A su vez, la sabiduría será definida como la "ciencia de la felicidad" (Leibniz AVI 1, 457), o "de lo óptimo" (Leibniz $A$ IV 1,36).

Dios es justo (prudente hacia las criaturas) porque ante todo es prudente (quiere su propio bien). Puesto que es sabio, le placen las cosas óptimas o más armoniosas.Y él mismo es la harmonia rerum. Por ende, un mundo con criaturas racionales que quieran alabarlo por su sabiduría y su justicia constituye el mejor reflejo de su propia armonía. Por ello quiere las cosas óptimas. Porque la justicia redunda en su propio bien (la multiplicación de su propia armonía). No hay aquí ningún atisbo de obligación que pese sobre Dios respecto de ley moral alguna. Más aun, Leibniz ratifica la tesis hobbesiana según la cual Dios tiene derecho pleno hacia todas las cosas, y afirma que lo que quiere el ser omnipotente es justo (Leibniz $A$ IV 1,10). Solo que, en Leibniz, la sabiduría complementa el derecho absoluto de Dios (y su posible arbitrariedad) con la prudencia hacia los otros (Leibniz $A$ VI 1, 444-445).

Cabe notar que, en los Elementa juris naturae, Leibniz parece seguir concibiendo la necesidad moral en los términos weigelianos, como un análogo jurídico-moral de la necesidad fisica. Sigue definiendo al derecho y a la obligación como cualidades morales, que nada son, dice, sino "cualidades del hombre bueno" (Leibniz AVI 1, 465). En el Specimen demonstrationum politicarum de 1669, Leibniz escribe que "la necesidad del derecho sobre la gente, cuyo objetivo es justo $[\ldots]$ es equivalente a la necesidad de hecho" (Leibniz $A$ IV 1,56). Y explica esta afirmación apelando a la "preclara" voz de Papiniano, según el cual

[...] las cosas que dañan nuestra piedad, nuestra estima, nuestra vergüenza y (como se dijera generalmente) que están contra las buenas costumbres, esas cosas debemos creer que no se pueden hacer. (Leibniz $A$ IV 1, 56)

En este sentido, la necesidad moral alude a la actitud del hombre bueno frente a aquello que es justo, una actitud de acatamiento, de restricción de la propia voluntad. Pero Leibniz, en estos escritos, nunca atribuye esta necesidad moral a Dios. 


\section{El principio de lo mejor}

$\Psi_{\text {portancia en su esquema argumental. En ese período, y en el }}^{\text {acia } 1670-1671 \text {, Leibniz introduce un cambio de enorme im- }}$ marco de los Elementa juris naturae, decide sustituir a la prudencia por el amor en su definición de la noción de justicia (que ahora es definida como el hábito de amar a los otros) (Leibniz $A$ VI 1, 465). Asimismo, afirma expresamente que el derecho es una ciencia que depende de las definiciones y las demostraciones, y que sus principios poseen verdad eterna, en tanto son verdades condicionales (conditionalia) (Leibniz AVI 1, 460-461). Esto ratifica su posición intelectualista respecto del contenido del derecho natural. Sin embargo, el cambio más importante que introduce tiene lugar en dos escritos metafisicos de enorme importancia: el Von der Allmacht und Allwissenheit Gottes und der Freiheit des Menschen (primer escrito de Leibniz que nos ha llegado consagrado a plantear una defensa de la justicia divina) y la carta a Magnus Wedderkopf de mayo de 1671 (primer esbozo de una metafísica que va de la demostración de la existencia de Dios, fundada en el principio de razón suficiente, a la existencia del mundo máximamente armonioso y a la exculpación de Dios por la existencia del pecado). En ambos escritos, la modificación vital que aparece es que Leibniz deja de lado el deseo de alabanza, como eventual motivo de Dios para ser justo con las criaturas, y pasa a sostener simplemente que Dios quiere lo mejor, lo más perfecto o lo más armonioso, diciendo que esto es de algún modo esencial a Dios, y que Dios se encuentra necesitado a ello.

Así, Leibniz escribe:

[...] quien es omnisciente quiere aquello que considera óptimo, puesto que resulta consustancial a la sabiduría el querer lo óptimo y quien niegue esto está trastocando los términos. Pues, si se es bueno, se quiere (cuando se comprende su naturaleza) lo mejor -tal y como dice Aristóteles-, si es que lo reconoce.Y, como quien es omnisciente conoce lo mejor, de ahí se sigue que lo quiere. Al ser omnisciente quiere aquello que considera lo mejor $\mathrm{y}$, como es todopoderoso, hace lo que quiere; luego de ahí se sigue que haya de consentir el pecado, si considera que es lo mejor. (Leibniz Roldán, 70 / $A$ VI 1, 544)

Sin embargo, como Dios es la mente más perfecta, es imposible que él mismo no sea afectado por la armonía más perfecta, y por tanto, también lo es que no sea necesitado hacia lo óptimo por la misma idealidad de las cosas. Lo cual en nada disminuye la libertad. Puesto que la suprema libertad es ser compelido a lo que es óptimo por la recta razón [...] De aquí se sigue que todo lo que ha sucedido, sucede o sucederá es lo óptimo, y por tanto es necesario, pero como dije, con una necesidad que nada quita a la libertad, puesto que nada quita a la voluntad y al uso de la razón. (Leibniz $A$ II 1,117) 
Como se ve, el "principio" de la harmonia rerum se consolida como razón determinante de la acción divina. Pero ahora, ese principio se complementa con el esbozo de una teoría de la voluntad o de la acción voluntaria, según la cual es "consustancial" a la voluntad del sabio (quien comprende qué es lo óptimo) el querer lo mejor. En este contexto, Leibniz emprende, ahora, una crítica severa contra toda indiferencia de equilibrio en la voluntad. Nadie puede elegir qué querer, solo se puede querer lo mejor (Leibniz $A \mathrm{VI}$ 1,544-546; $A$ II 1,117-118). Esto parece elevar la armonía universal al rango de razón necesitante para la voluntad divina (si bien Leibniz no traza aún la distinción entre razón necesitante y razón determinante).

En este viraje argumental, sostengo, entra en escena ya, en sus primeras formulaciones, lo que luego constituirá en la filosofia leibniziana el principio de lo mejor, todavía atado a su fuente originaria (la harmonia rerum). Aquí, la tesis según la cual Dios quiere lo mejor aparece como regla que rige toda acción divina, y que explica, por consecuencia, su justicia para con las criaturas. Es, por ende, un principio, que explica ante todo las acciones divinas, y su primera misión en la filosofia leibniziana es la de aportar aquello que una teoría de la moralidad (basada en la ley natural) claramente no podía, para Leibniz, brindar: una razón que determine a Dios a ser bondadoso y justo hacia las criaturas. Esa misión se realiza, como puede verse en la carta a Wedderkpof, sosteniendo que Dios es conducido por su propia naturaleza a elegir lo mejor, y que, por tanto, lo que Dios ha producido es lo óptimo.

\section{Conclusiones}

二 ste recorrido permite formular algunas conclusiones impor-

Ctantes. En primer lugar, el joven Leibniz, entre 1663 y 1671, necesita buscar una razón que permita explicar por qué Dios habría de ser justo, o incluso bondadoso, en relación a las criaturas humanas. Ello revela, sin más, que, para el Leibniz de estos años, Dios no está sometido a ninguna obligación de tipo moral y/o jurídica, que pudiera imponerle la necesidad de obrar con justicia. La concepción de la moralidad como un orden cuasi-jurídico basado en la existencia de una ley moral o ley natural, que Leibniz toma de su formación jurídica y del debate de la época en torno al iusnaturalismo moderno, lo conduce a buscar una fundamentación extra-jurídica, metafísica, de la justicia divina, por la sencilla razón de que Dios no está obligado a acatar ley alguna.

Esta inimputabilidad o anupeúthunía divina se debe, en segundo lugar, a que, para el joven Leibniz, la obligatoriedad de la ley moral parece tener un doble fundamento: las nociones o definiciones de los términos (o la 
adecuación del contenido de la ley a la noción de justicia) y la existencia de un poder coercitivo que motive a cumplir la ley mediante la amenaza de una pena.Y, obviamente, no hay poder coercitivo alguno capaz de obligar a Dios. Leibniz parece tener una concepción intelectualista de la justicia (contenido de la ley), pero una concepción semi-voluntarista de la vigencia del derecho natural (o del orden jurídico basado en tal derecho). Tal concepción puede verse expresada en la carta a Conring de enero de 1670, en la que Leibniz distingue dos niveles: el de los dos fundamentos de "toda la eficacia de lo justo y lo equitativo" (la existencia de Dios y la inmortalidad del alma), y el de las reglas fundamentales de la justicia o de la utilidad pública (que a nadie le sea quitada su posesión, versión reformulada del jus strictum, y que a cada uno se le dé cuanto es necesario para la utilidad pública) (Leibniz $A$ II 1,30). Lo justo es justo per se, pero la obligación de cumplir con las reglas del derecho natural depende, en definitiva, de la existencia de Dios como garante de su cumplimiento. Aun cuando Leibniz defina la obligación como una necesidad moral, ella sería una "suma estupidez" si no estuviera acompañada por la enorme utilidad que significa evitar el castigo divino (Leibniz $A$ II 1,30).

Por último, la búsqueda leibniziana de una razón para la justicia divina conduce, según creo, a introducir en su filosofia la tesis que afirma que Dios quiere lo mejor, o incluso que está "necesitado hacia lo óptimo". Esta tesis constituye, según creo, la primera versión de lo que Leibniz habría de distinguir, en años posteriores, como el principio de lo mejor o de la conveniencia. Hacia 1671, esta tesis aparece como principio o razón que explica todas las acciones divinas, que surge como consecuencia del principio de razón suficiente (incorporado ya hacia 1668) y a partir de la fuente originaria que fuera su primera respuesta al problema aquí abordado: la harmonia rerum. El orden del universo es eco o reflejo de la estructura ontológica trinitaria del Ente primero: poder-sabiduría-amor.Y Dios, el ser máximamente sabio, es deleitado por la máxima armonía, como lo garantizan las definiciones que Leibniz construye hacia 1670-1671. Por ello, en definitiva, Leibniz podrá prescindir, ya en 1671, de la alabanza como excusa divina para ser prudente hacia los seres humanos. Dios es justo porque quiere lo mejor, lo máximamente armonioso, dado que la voluntad no puede hacer otra cosa que dirigirse hacia lo que el entendimiento considera óptimo.Y como la justicia (es decir, el amor desinteresado hacia todos) es la virtud que concilia el bien propio con el bien de los otros, ella parece la clave para lograr un mundo que refleje la suma perfección divina, maximizando el bien de todos tanto como lo permite la armonía universal. Porque es propio de la sabiduría (ciencia de lo óptimo) elegir para sí mismo el bien que sea, al mismo tiempo, justo o públicamente bueno (Leibniz $A$ IV 1, 46). 
Hay aquí un cambio importante, y es que aparece una línea argumental basada ya no en el deseo divino de alabanza, sino en la propia naturaleza de la voluntad, concebida desde una perspectiva fuertemente intelectualista. La voluntad tiende al bien per se, y eso implica que su elección es siempre determinada por el juicio del intelecto referido a lo óptimo. El Dios justo es ahora un Dios sabio, más bien que un Dios prudente. Un Dios que tiende al bien en general, y no solo a su bien considerado en particular (aun cuando ambos bienes ciertamente convergen). En este viraje puede verse la importancia que adquiere en la filosofia de Leibniz, ya en esta época temprana, la tesis de la elección divina de lo mejor como fundamento explicativo de las acciones de Dios. ${ }^{5}$

\section{BIBLIOGRAFÍA}

Antognazza, M. R. (1999), "Immeatio and Emperichoresis. The Theological Roots of Harmony in Bisterfeld and Leibniz”, en S. Brown (1999) (ed.), The Young Leibniz and his Philosophy (1646-76) (Dordrecht: Kluwer Academic Publishers, 41-64).

Brown, S. (1999) (ed.), The Young Leibniz and his Philosophy (1646-76) (Dordrecht: Kluwer Academic Publishers).

Garber, D. y Ayers, M. (2008) (eds.), The Cambridge History of Seventeenth-Century Philosophy (Cambridge: Cambridge University Press).

Grocio, H. $(D J B P)$, Del derecho de la guerra y de la paz (Madrid: Reus, 1925) (citado indicando libro, capítulo y sección).

Haakonssen, K. (1998), "Divine/Natural Law Theories in Ethics", en D. Garber y M. Ayers (2008) (eds.), The Cambridge History of Seventeenth-Century Philosophy (Cambridge: Cambridge University Press, 1317-1357).

Hobbes, T. (1651), Leviatán, o la materia, forma y poder de una república eclesiástica y civil (México: FCE, 1980).

Leibniz, G. W. (A) Leibniz, G. W. Sämtliche Schriften und Briefe, (Darmstadt, Leipzig, Münster: Akademie-Verlag, 1923 y ss).

Leibniz, G.W. (Dutens), G. W. Leibnitii Opera Omnia, ed. L. Dutens, 6 vols. (Ginebra: 1768).

Leibniz, G. W. (Grua), Testes inédits d'après les manuscrits de la bibliothèque provinciale de Hanovre, ed. G. Grua (Paris: Presses Universitaires, 1948).

\footnotetext{
${ }^{5}$ Este trabajo se realizó en el marco del proyecto financiado por la ANPCyT PICT 20170506 "La Ciencia General de Leibniz como fundamentación de las ciencias: lógica, ontología y filosofía natural".
} 
Leibniz, G. W. (Mollat), Mitteilungen aus Leibnizens ungedruckten Schriften, ed. G. Mollat (Leipzig: Hassel, 1893).

Leibniz, G. W. (Roldán), Escritos en torno a la libertad, el azar y el destino, comp. Concha Roldán Panadero (Madrid:Tecnos, 1990).

Leibniz, G. W. (Salas), Escritos de filosofía jurídica y política, Jaime de Salas Ortueta (comp.) (Madrid: Editora Nacional, 1984).

Piro, F. (1999), "Leibniz and Ethics: the Years 1669-72", en S. Brown (1999) (ed.), The Young Leibniz and his Philosophy (1646-76) (Dordrecht: Kluwer Academic Publishers, 147-167).

Pufendorf, S. (DJN), De jure naturae et gentium libri octo (Londini Scanorum: Adami Junghans, 1672) (citado indicando libro, capítulo y sección).

Pufendorf, S. (EJU), Elementorum jurisprudentiae universalis libri II, (Hagae - Comitis: Ex Typographia Adriani Vlacq, 1660) (citado indicando libro, definición y sección).

Rateau, P. (2008), La question du mal chez Leibniz: fondaments et élaboration de la Théodicée (Paris: Honoré Champions Éditeur).

Schneewind, J. B. (2010), La invención de la autonomía: una historia de la filosofía moral moderna (México: FCE).

Stahl, D. (1686), Compendium metaphysicae in XXIV tabellas redactum (Francofurtum). Münchener DigitalisierungsZentrum, Digital Bibliothek. Permalink: http://www. mdz-nbn-resolving.de/urn/resolver.pl?urn=urn:nbn:de:bvb:12-bsb10943995-0.

Suárez, F. (DL), Tractatus de legibus ac Deo legislatore in decem libros distributos ( $\left.1^{\circ} \mathrm{ed} .1612\right)$ (Neapoli: ex Typis Fibrenianis, 1872) (citado indicando libro, capítulo y sección).

Thomasius, J. (1667), Philosophia practica (1º ed. 1661) (Lipsiae, Editio secunda).

Tomás de Aquino (Summa Theologiae), Corpus Thomisticum. S. Thomae de Aquino Opera Omnia, recognovit ac instruxit Enrique Alarcón automato electronico. (Pompaelone ad Universitatis Studiorum Navarrensis). URL $=<$ http://www.corpusthomisticum. org/iopera.html>.

Recibido: 09-07-2019; aceptado: 30-09-2019 